\title{
Mitigation of thermal distortion in wire arc additively manufactured Ti6Al4V part using active interpass cooling
}

\author{
Bintao Wu ${ }^{\mathrm{a}}$, Zengxi Pan ${ }^{\mathrm{a} *}$, Guangyu $\mathrm{Chen}^{\mathrm{b}}$, Donghong Ding ${ }^{\mathrm{c}}$, Lei Yuan ${ }^{\mathrm{a}}$, Dominic \\ Cuiuria ${ }^{\mathrm{a}}$, Huijun $\mathrm{Li}^{\mathrm{a}}$
}

\begin{abstract}
a. School of Mechanical, Materials, Mechatronic and Biomedical Engineering, University of Wollongong, Wollongong NSW 2522, Australia

b. Welding Engineering and Laser Processing Centre, Building 46, Cranfield University, Bedford, MK43 0AL, UK

c. School of Mechatronic Engineering, Foshan University, Foshan Guangdong 528000, China
\end{abstract}

\begin{abstract}
In this study, active interpass cooling using compressed $\mathrm{CO}_{2}$ was innovatively employed in the wire arc additively manufactured Ti6Al4V process with the aim of mitigating part distortion. A comparative analysis between simulation and experimental results was performed to explore the effects of active interpass cooling on the thermal behaviours, geometric features and distortion levels of deposit. The results show that active interpass cooling with $\mathrm{CO}_{2}$ gas is an effective means of reducing WAAM part distortion by increasing heat dissipation and reducing heat accumulation within the deposition. It can contribute to a maximum reduction of $81 \%$ in longitudinal distortion and $69 \%$ in transverse distortion for the wall structures produced in this study. Compared to the cooling gas flow rate, cooling time alternation is more effective in mitigating WAAM-part distortion due to more effective heat dissipation per unit time. The findings reveal that using active interpass cooling in WAAM can offer significant cost and build time savings, as well as provide conditions for the improvement of WAAM part quality.
\end{abstract}


Key words: Wire Arc Additive Manufacturing (WAAM); Ti6A14V; Active interpass cooling; Distortion.

*Corresponding author:

Zengxi Pan; Tel: +61-2-42215498; Email address: zengxi@uow.edu.au;(Z. Pan).

\section{Introduction}

In recent years, wire arc additive manufacturing (WAAM) has attracted significant attention in industrial manufacturing sectors due to its ability to create large metal structures with high buy-to-fly ratios[1]. Uniquely, WAAM employs either Gas Metal Arc Welding (GMAW), Gas Tungsten Arc welding (GTAW), or Plasma Arc Welding (PAW) as a fusion source, commercial welding wire as a feedstock and an articulated industrial robot as a motion mechanism to build components in a layer-bylayer approach. Compared to powder feedstock and alternative heat sources, such as electron beam and laser, the component parts of a WAAM system represent a significant cost saving[2]. Hitherto, a variety of engineering materials, such as titanium alloy, steel, aluminum alloy, and nickel-base alloy, have been successfully used with the WAAM process. High deposition rates for large metal components have been achieved, allowing significant material savings and promoting manufacturing efficiency[3]. Among the engineering materials used with WAAM, Ti6A14V alloy attracts much attention due to its frequent use in aviation and aerospace applications, where these fabricated structures normally suffer from extremely low manufacturing efficiency and high cost when using conventional subtractive fabrication methods[4].

Thermal distortion often affects every part of wire arc additively manufactured 
components, since the feed materials experience non-uniform thermal expansion and contraction under alternate heating and cooling cycles during layered deposition $[5,6]$. Mukherjee et al.[7] reported that the thermal distortion in additively manufactured parts is a result of the combined effects of material properties, geometric features, deposition pathways, process parameters and preheating or cooling conditions. Denlinger et al. [8] found that thermal distortion is able to accumulate along the build direction due to ineffective heat dissipation and the resultant introduced preheat for the subsequent layer. It is well known that a WAAM-deposited component exhibits different types of distortion, including longitudinal and transverse shrinkage, bending distortion, angular distortion and rotational distortion[9], resulting in imprecise geometry of the final part and also creating residual stress that may lead to leading to failure during service [10]. Hence, it is necessary to control the thermal distortion to an acceptable range to ensure adequate quality of WAAM parts.

To address this issue, it is critical to predict the thermal state or the internal stress field changes in the deposition. A study was conducted by Cao et al.[11] to examine the distortion characteristics and residual stress distribution in WAAM-fabricated Ti6Al4V structures, and proposed that preheating of the substrate can significantly mitigate residual stress and distortion. Montevecchi et al.[12] and Ding et al.[13] introduced a number of simulation methods to predict distortion during deposition, and satisfactory results were achieved by experimental validation.

To date, both thermal and mechanical methods can be used to reduce the distortion in WAAM-fabricated parts. Thermal methods mainly consist of heat input 
control and post-fabrication heat treatment. Typically, heat input control within an acceptable range only reduces the part distortion to a limited extent, while post heat treatment is time-consuming, costly and limited by the size of the produced component[14]. Attempts have been made to develop efficient and low cost equipment to reduce distortion, for example, using interpass cold rolling and designing suitable manufacturing fixtures[14]. However, the interpass cold rolling technique is only feasible for deposited parts with simple shapes such as straight walls, due to geometrical limitations of the rolling process[15]. Designing a variety of fixtures to minimize flexibility of work pieces obviously brings more labour and higher costs for manufacturing[16]. Dynamically Controlled Low Stress No Distortion (DC-LSND) welding, which use a cryogen, CO2 snow, as the cooling source to locally cool the weld, has been proven to be an effective method for reducing welding-induced stress and distortion. As WAAM and welding share the similar welding physics, active interpass cooling using compressed $\mathrm{CO}_{2}$ has been introduced into WAAM process recently [17]. It was found that this innovative approach provided benefits to the WAAM-produced Ti6AL4V alloy, contributing to an appealing surface finish with refined microstructure, enhanced tensile strength and improved microhardness[18].

In this study, an active interpass cooling process, where compressed $\mathrm{CO}_{2}$ is used to cool the area behind the heat source, is employed to reduce flexural distortions in WAAM Ti6Al4V wall structures. By means of experiment and simulation, the thermal histories, geometrical features and distortional characteristics are evaluated for 
components produced with and without interpass cooling. Moreover, a comparative analysis between results is presented, aiming to discuss the feasibility of adding sequential active interpass cooling into the WAAM process to control part distortion.

\section{Experimental Procedures}

\subsection{Experiment setup}

As shown in Fig.1, the apparatus comprises a "cold" wire feeder, a 200A-rated GTAW power source, a travel mechanism and a $\mathrm{CO}_{2}$ gas cooling system. Commercial Ti6Al4V welding wire with a diameter of $1.2 \mathrm{~mm}$ was selected as feedstock material and Ti6Al4V plate with dimensions of $200 \mathrm{~mm} \times 65 \mathrm{~mm} \times 6 \mathrm{~mm}$ was used as substrate. The chemical compositions of as-received materials are listed in Table 1. A $150 \mathrm{~mm}$ long trailing gas shield was placed behind the GTAW torch to provide localized protection against oxidation during the deposition process.

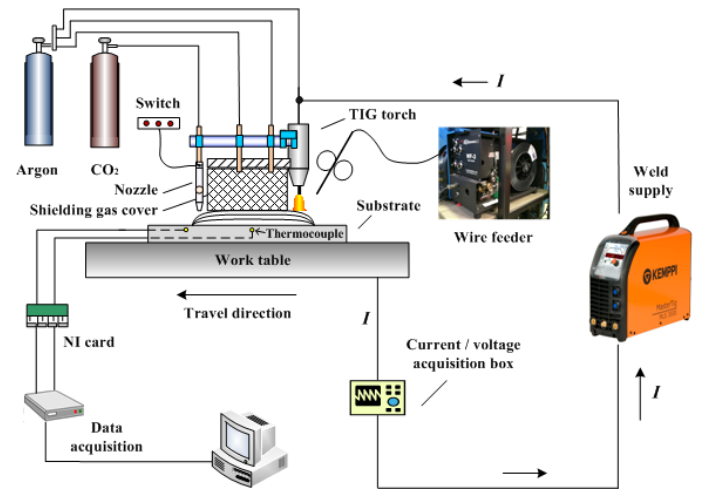

(a)

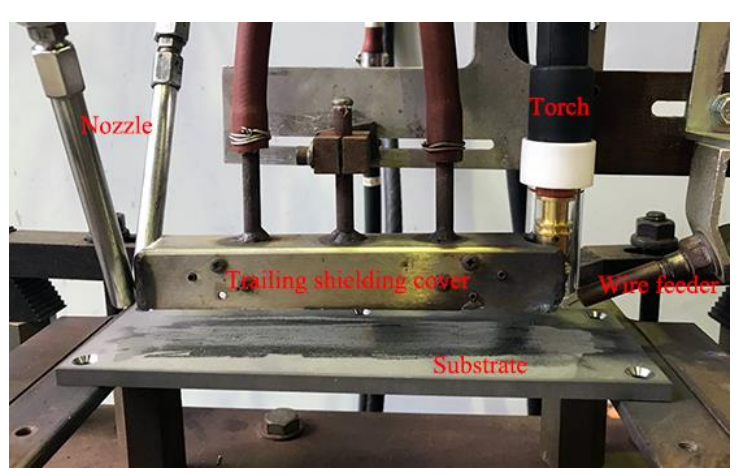

(b)

Fig.1 The manufacturing system used in this study: (a) schematic diagram; (b) photograph of deposition process

Table 1 Chemical composition of Ti6Al4V (wt.\%).

\begin{tabular}{ccccccccc}
\hline Composition & $\mathrm{Al}$ & $\mathrm{V}$ & $\mathrm{C}$ & $\mathrm{Fe}$ & $\mathrm{H}$ & $\mathrm{N}$ & $\mathrm{O}$ & $\mathrm{Ti}$ \\
\hline Wire (ASTM B863) & 6.20 & 4.0 & 0.08 & 0.40 & 0.015 & 0.05 & 0.20 & Bal. \\
\hline Substrate (ASTM B265) & 6.10 & 4.0 & 0.08 & 0.30 & 0.015 & 0.03 & 0.20 & Bal. \\
\hline
\end{tabular}


In this study, active interpass cooling was achieved by delivering a stable $\mathrm{CO}_{2}$ stream through a commercially-available spray nozzle located behind the trailing gas shield cover, as displayed in Fig.1. The cooling temperature achieved by the compressed $\mathrm{CO}_{2}$ was measured at approximately $-78^{\circ} \mathrm{C}$. As the relatively turbulent $\mathrm{CO}_{2}$ flow may induce arc disruption during deposition, the $\mathrm{CO}_{2}$ spray was started immediately after the deposited layer was completed and the arc was extinguished. Subsequently, the cooling spray was passed over the newly deposited layer with the same speed as the deposition, and it was stopped when the spray arrived at the end of the wall. Three nozzle types were alternatively tested, delivering $\mathrm{CO}_{2}$ gas flow rates of $320 \mathrm{~g} / \mathrm{min}, 730 \mathrm{~g} / \mathrm{min}$ and $1460 \mathrm{~g} / \mathrm{min}$ respectively. During the build, the thermal profiles were continuously monitored by a thermocouple which was attached to the mid-length of the substrate and offset by $20 \mathrm{~mm}$ from the deposition path, as shown in Fig.2. The recorded data was processed using LabVIEW software.

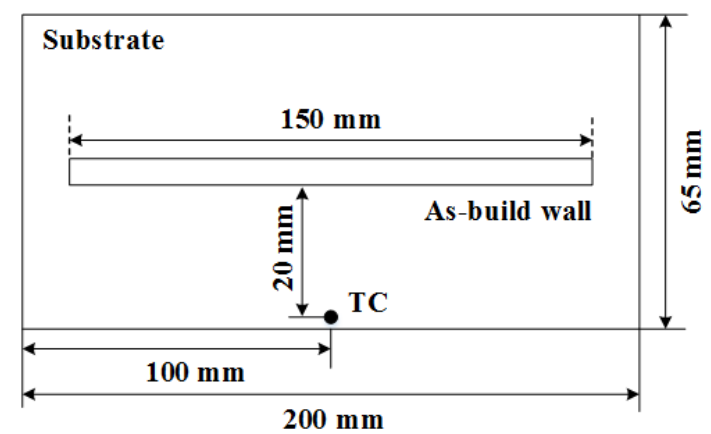

Fig.2 Schematic of temperature measurement location for the thermocouple

Six straight wall structures were produced with different process parameters using the described additive manufacturing system. Various cooling gas flow rates and cooling times were selected to explore the influence of different cooling strategies on thermal distortion. Accordingly, specimens were divided into three groups by cooling 
conditions, as listed in Table 2. Group I, with the test specimen coded as S1, refers to the deposition without interpass cooling, and serves as a reference. The Group II with specimens from S2 to S4 and Group III with specimens S2, S5 and S6 were designed to investigate the effects of cooling gas flow rate and cooling time, respectively. For Group III, the cooling time were represented by the ratio of travel speeds and compares as a relative time for the investigation due to limited ability to control in deposition. Here, it needs to be indicated that due to the use of different travel speed, the progressive reduction of the heat input from welding torch may act to minimize the heat accumulation and reduce the distortion of build part in addition to the cooling effects by gas $\mathrm{CO}_{2}$. However, this phenomenon was found to be greatly weakened when forced convective cooling applied in multiple of layers. This is because active interpass cooling has been used to establish a similar thermal boundary condition at the multilayer position compensating for the poor heat dissipation at the multilayer, which provides an effective way of eliminating the difference in heat dissipation between upper and lower layers, and then maintaining stable heat dissipation characteristics, with associated benefits to the distortion improvement. The detailed parameter design for the cooling process is provided in Table 2, and the deposition parameters are listed in Table 3. Welding grade argon (99.995\% purity) was used as shielding gas for both welding torch and trailing shield cover. 
Table 2 Parameter design for cooling process

\begin{tabular}{ccccc}
\hline Group & Deposition sample & $\mathrm{CO}_{2}$ flow rate $(\mathrm{g} / \mathrm{min})$ & Travel speed $(\mathrm{mm} / \mathrm{min})$ & cooling time \\
\hline I & $\mathrm{S} 1$ & 0 & 150 & N/A \\
II & $\mathrm{S} 2$ & 320 & 150 & 1 \\
& $\mathrm{~S} 3$ & 730 & 150 & 1 \\
& $\mathrm{~S} 4$ & 1460 & 150 & 1 \\
III & $\mathrm{S} 2$ & 320 & 150 & 1 \\
& $\mathrm{~S} 5$ & 320 & 230 & 0.65 \\
& $\mathrm{~S} 6$ & 320 & 300 & 0.5 \\
\hline
\end{tabular}

Table 3 Welding and deposition parameters

\begin{tabular}{ll}
\hline Processing parameters & Details \\
\hline Welding current & $140 \mathrm{~A}$ \\
Arc voltage & $15.5 \mathrm{~V}$ \\
Wire feed speed & $1060 \mathrm{~mm} / \mathrm{min}$ \\
Distance from electrode to workpiece & $3 \mathrm{~mm}$ \\
Angle between electrode and filler wire & $60^{\circ}$ \\
Flow rate of argon in GTAW welding torch & $15 \mathrm{~L} / \mathrm{min}$ \\
Flow rate of trailing shield & $15 \mathrm{~L} / \mathrm{min}$ \\
Number of deposited layers & 10 \\
\hline
\end{tabular}

\subsection{Distortion measurement}

To measure the distortion of the as-deposited specimens, a 3D laser profile scanner with a resolution of $0.02 \mathrm{~mm}$ was used and the recorded data was processed with commercial MATLAB software.

\subsection{Modeling process}

\subsubsection{Finite element model}

As shown in Fig.3, only half of the symmetrical substrate is modeled in order to reduce the simulation time. In the finite element model, the minimum mesh unit has a dimension of $1.3 \mathrm{~mm} \times 1.5 \mathrm{~mm} \times 0.9 \mathrm{~mm}$. ANSYS SOLID5 $3 \mathrm{D}$ coupled-field element with 8 nodes were adopted. SOLID5 has 3D magnetic, electric, thermal, 
piezoelectric and structural field capability with limited coupling between each field. In this study, thermal and structural field coupling was utilized, and the thermal and mechanical processes were solved at the same time. The finite element model generated 5396 units and 7804 nodes during the simulation process. Elements of the bead were deactivated before the calculation. During the analysis, bead elements radiated by the arc in each time step were activated when heat source moving along the bead during the process.

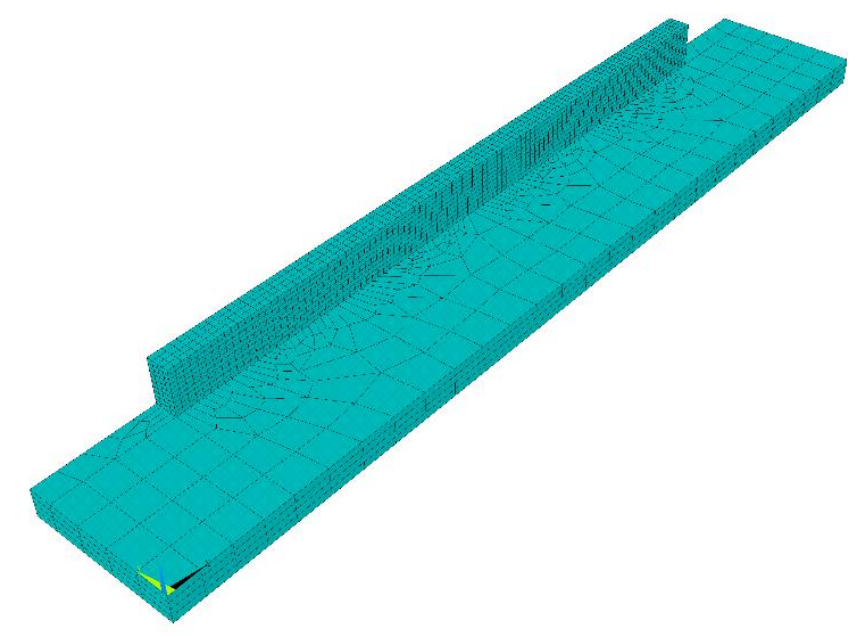

Fig.3 3D finite element mesh for one half of build part

\subsubsection{Heat source}

During the welding process, the heat input of the arc was simulated by applying heat flux loads on the surface of the bead. The heat flux loads were distributed by the following expression[14]:

$$
q(x, y)=3 P \cdot \eta \exp \left(-3\left(x^{2}+y^{2}\right) / R^{2}\right) /\left(\pi R^{2}\right)
$$

where $q(\mathrm{x}, \mathrm{y})$ is heat flux density; $P$ is the power of welding arc; $\eta$ is the welding arc efficiency $(\eta=0.7) ; x^{2}+y^{2}$ is the square of the distance from the calculation point to 
the center of the arc and $R$ is the radius of the $\operatorname{arc}(R=10 \mathrm{~mm})$.

During the welding process, heat flux loads would be applied to the radiated area of the arc at the beginning of each step. Then the thermal-structural calculation would be carried out. After the calculation, the heat flux loads would be removed. And a new welding step would be initiated. The position of the heat flux loads was moving step by step in the same speed of the welding torch.

\subsubsection{Cooling process}

The air cooling was simulated by applying a convention coefficient on the surface of the bead and the value of the coefficient is 400 . The number of the steps to simulate each air-cooled deposition process (Group I) was pre-defined, but determined by the temperature of a reference node (indicated as TC in Figure 2). At the end of each air-cooling step, temperature at the reference point would be checked at the end of each step. Each cooling step lasted for 100 seconds. If the temperature was higher than the reference temperature, another cooling substep would be added. Once the temperature of the reference point reached room temperature, the natural cooling process would be terminated and the welding process for the next layer would be initiated.

In the simulation of deposition with $\mathrm{CO}_{2}$ interpass cooling (Group II and Group III), instead of applying a relatively larger value of co-efficiency. Nodes at the $\mathrm{CO}_{2}$ spray cooling position were applied with temperature constraints using the data measured respectively after each cooling process. During the forced cooling, the temperature of the cooled dropped down in a very short time. Therefore, by applying 
the cooled temperature constraints directly to the cooled nodes, temperature of the nodes also dropped down to the same point immediately. As the gas nozzle moved along the welding direction, the cooling position changed with time. Therefore, at the beginning of each step, temperature constraints of the position that had just been cooled down in the previous step would be removed and new temperature constraints would be added to the new cooling region. By using this method, thermophysical properties of $\mathrm{CO} 2$ gas was not directly used and fluid-structure coupling analysis was being avoided.

\subsubsection{Boundary conditions and material attributes}

A reference temperature was set to indicate the initial temperature at the beginning of the simulation. Reference temperature was also used to simulate room temperature during the calculation. Displacement constraints that simulate the fixture of the workpiece have great influence on the stress calculation and displacement results. Four corners of the plate were set to rigid displacement in all three directions to simulate the constraints of the fixture bolts during the deposition process, as shown in Fig.4. After process completion, the constraints at these nodes were deleted to simulate the removal of the bolts after the process. Also, in order to avoid drift of the entire structure, one corner node of the plate was set to full constraint and three nodes at the other three corners were set to rigid displacement in the vertical direction. Displacements parallel to the transverse direction were constrained on the symmetrical face. 


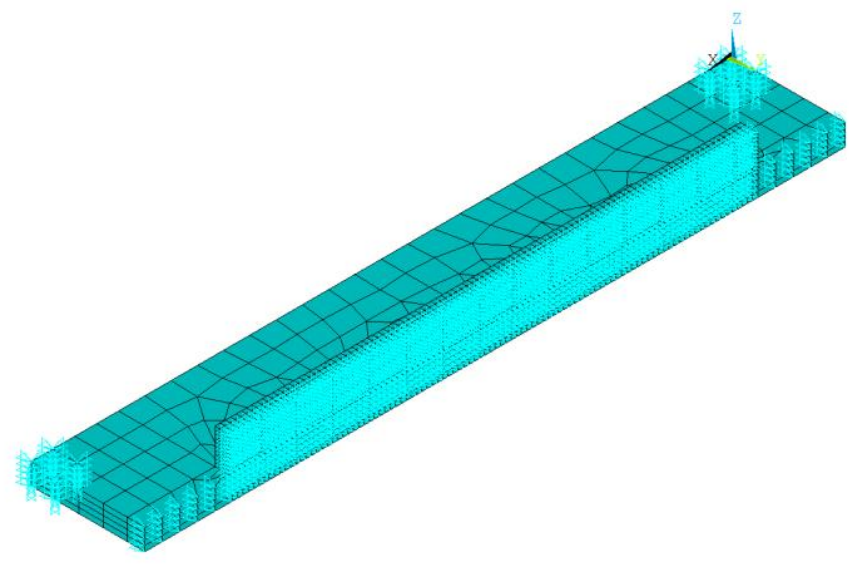

Fig.4 The boundary conditions for the simulated model

Temperature field simulation of the welding process is a non-linear transient analysis. Properties of the material, such as yield strength, elastic modulus, specific heat and thermal conductivity are temperature-dependent. Therefore, property data is associated with a temperature table, as shown in Table 4. Poisson's ratio is considered to be constant since the change of Poisson's ratio with temperature is quite small. Therefore, it was set to 0.3 during the whole simulation process.

The workpiece was with encompassed by varied thermal mediums. Heat transfer from the top surface of the workpiece was mainly conducted by air, and heat transfer from the bottom surface was considered to be forced convection to the worktable. As a result, heat transfer coefficients were set differently in different areas. No heat transfer coefficient was set on the symmetrical face.

The mechanism of the fluid flow is with no double very critical to the temperature field, residual stress and distortion of the AM process. However, fluid-structure coupling method which can be used to simulate is a rather complex multiphysics problem and involves both CFD and FEM theories. This kind of 
simulation is quite time-consuming and has a much higher requirement for computing hardware. In our study, we use FEM alone to provide thought of using a relatively simplier and more effective way to simulate the cooling process.

Table 4 Material properties used in this study

\begin{tabular}{c|c|c|c|c|c|c|c}
\hline $\begin{array}{c}\text { Temperature } \\
{ }^{\circ} \mathrm{C}\end{array}$ & $\begin{array}{c}\text { Conductivities } \\
\mathrm{W} /(\mathrm{m} \cdot \mathrm{K})\end{array}$ & $\begin{array}{c}\text { Specific } \\
\text { heat } \\
\mathrm{J} /(\mathrm{kg} \cdot \mathrm{K})\end{array}$ & $\begin{array}{c}\text { Elastic } \\
\text { moduli } \\
\mathrm{Pa}\end{array}$ & $\begin{array}{c}\text { Poisson's } \\
\text { ratios }\end{array}$ & $\begin{array}{c}\text { Thermal } \\
\text { expansion }\end{array}$ & $\begin{array}{c}\text { Yield } \\
\text { stress/Pa }\end{array}$ & $\begin{array}{c}\text { Tangent } \\
\text { modulus/Pa }\end{array}$ \\
\hline 20 & 6.8 & 611 & $1.14 \mathrm{e} 11$ & 0.3 & $0.91 \mathrm{e}-5$ & $804 \mathrm{e} 6$ & $1.14 \mathrm{e} 10$ \\
100 & 7.9 & 678 & $1.1 \mathrm{e} 11$ & 0.3 & $0.91 \mathrm{e}-5$ & $620 \mathrm{e} 6$ & $1.1 \mathrm{e} 10$ \\
200 & 8.79 & 691 & $1.04 \mathrm{e} 11$ & 0.3 & $0.92 \mathrm{e}-5$ & $638 \mathrm{e} 6$ & $1.04 \mathrm{e} 10$ \\
300 & 10.47 & 703 & $0.98 \mathrm{e} 11$ & 0.3 & $0.93 \mathrm{e}-5$ & $552 \mathrm{e} 6$ & $0.98 \mathrm{e} 10$ \\
400 & 12.56 & 741 & $0.92 \mathrm{e} 11$ & 0.3 & $0.95 \mathrm{e}-5$ & $455 \mathrm{e} 6$ & $0.92 \mathrm{e} 10$ \\
500 & 14.24 & 754 & $0.84 \mathrm{e} 11$ & 0.3 & $0.97 \mathrm{e}-5$ & $377 \mathrm{e} 6$ & $0.84 \mathrm{e} 10$ \\
750 & 27 & 760 & $0.75 \mathrm{e} 11$ & 0.3 & $0.97 \mathrm{e}-5$ & $350 \mathrm{e} 6$ & $0.75 \mathrm{e} 10$ \\
1000 & 30 & 950 & $0.74 \mathrm{e} 11$ & 0.3 & $1 \mathrm{e}-5$ & $130 \mathrm{e} 6$ & $0.74 \mathrm{e} 10$ \\
1500 & 35 & 1092 & $0.57 \mathrm{e} 11$ & 0.3 & $1.15 \mathrm{e}-5$ & $40 \mathrm{e} 6$ & $0.57 \mathrm{e} 10$ \\
1700 & 14 & 1347 & $0.1 \mathrm{e} 11$ & 0.3 & $1.58 \mathrm{e}-5$ & $40 \mathrm{e} 6$ & $0.1 \mathrm{e} 10$ \\
\hline
\end{tabular}

\section{Results and discussion}

\subsection{Thermal behaviours during deposition}

Fig.5 shows the thermal profiles measured by thermocouple during the deposition process, with and without active interpass cooling. It is observed that when the welding torch moved along the travel direction, the temperature increased rapidly until a peak temperature was achieved. After completing the deposition of each layer, the temperature gradually decreased with natural cooling, but a much sharper drop in the temperature occurs with interpass cooling. As a result, the build time for the 10 deposited layers in this study was reduced by at least 80 percent when $\mathrm{CO}_{2}$ cooling was implemented, as comparably shown in Fig.5. It is evident that active interpass cooling in WAAM can offer a significant build-time saving through a dramatic 
reduction of interlayer dwell time, and thereby provides a means for improvement of manufacturing efficiency.

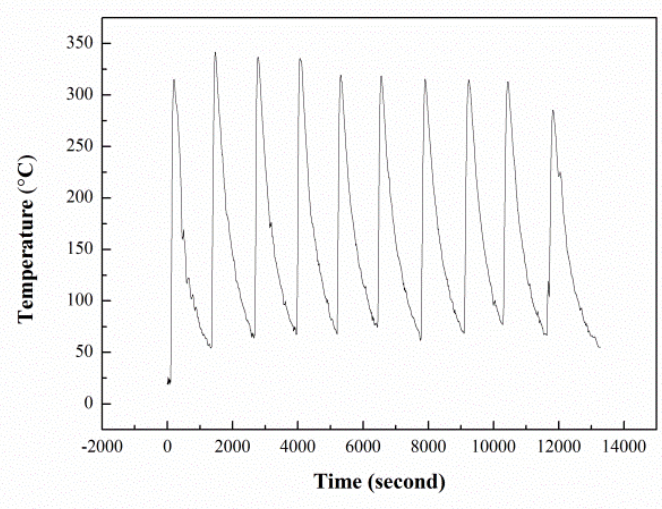

(a)

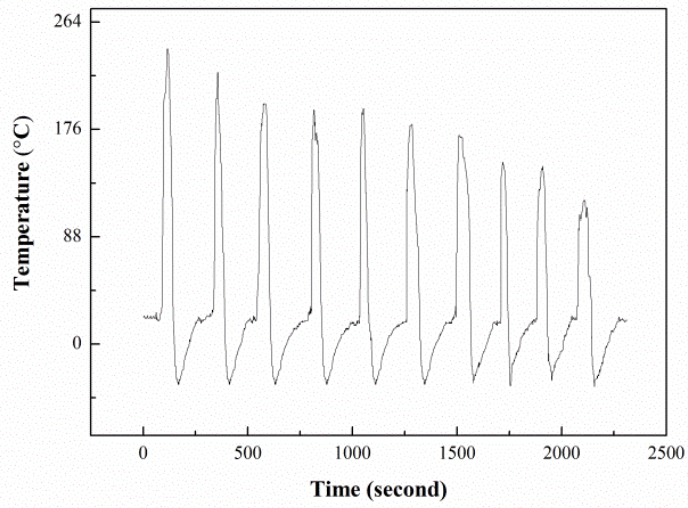

(b)

Fig.5 The temperature profiles of deposition (a) with natural cooling and (b) with active interpass cooling

Variations in thermal profile occur when the $\mathrm{CO}_{2}$ cooling gas flow rate or cooling time are changed during fabrication. Fig.6 compares the thermal histories of one selected layer in all five depositions using different cooling parameters. With increased $\mathrm{CO}_{2}$ gas flow rate from $320 \mathrm{~g} / \mathrm{min}$ (S2) to $1460 \mathrm{~g} / \mathrm{min}$ (S4), the peak temperature could be reduced by over $50 \%$ due to a significant increase in heat removal from the component after the previous layer was deposited. As well, this trend can be observed in processes with increased travel speeds (S2, S5 \& S6), whereby lower heat input brings likewise lower heat accumulation along the build direction. Hence, it is accepted that the combined effects of heat input, cooling gas flow rate and cooling time potentially determines the development of peak temperature, which could be related to the different cooling effects in the deposition. Additionally, active interpass cooling can cause uneven distribution of heat in the build part. Due to the increased thermal dissipation in the uppermost layer of deposit, 
the interior part produces a large difference between the highest and the lowest values that cooling rates may take. As the deposition suffered from uneven heat distribution, it expands irregularly in all directions, resulting in inhomogeneous stress and distortion to the build part.

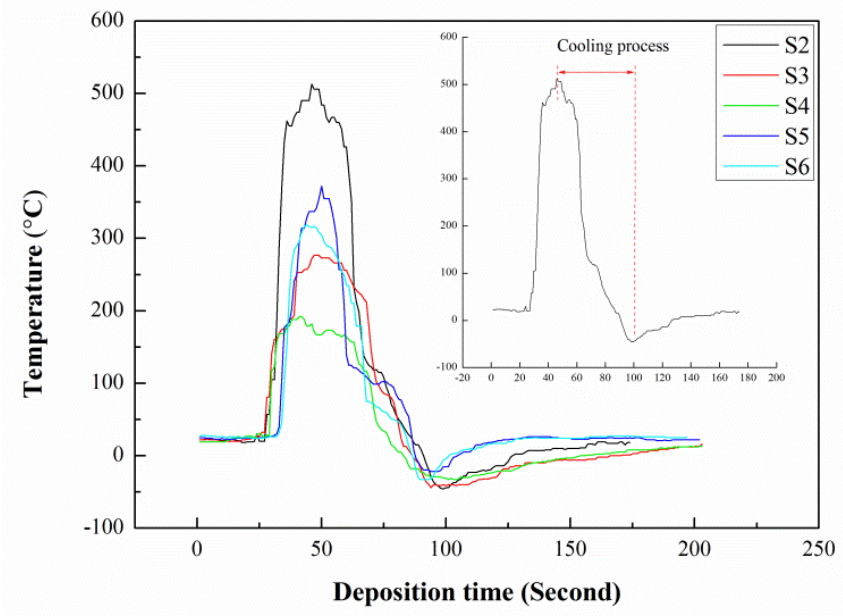

Fig.6 The thermal history of one selected layer with different active interpass cooling processes for S2 to S6

\subsection{Geometrical features}

Fig. 7 shows the geometrical features of as-deposited specimens in this study. Compared to the specimen produced with natural cooling (S1), when using active interpass cooling at the same travel speed (S2, S3 and S4) the average width of build walls was reduced by around $7 \%$, and average height increased by about $6 \%$. Due to the rapid cooling produced by compressed $\mathrm{CO}_{2}$, a decreasing amount of heat distributed in the previous deposition is considered as the part of heat input for the subsequent layer, contributing to lower temperatures in the molten pool and surrounding area, and thus a narrower layer weld bead. So, although active interpass cooling can be a tremendous advantage to promote manufacturing efficiency, the results have shown that the build geometry changes slightly. Unless, this effect is 
correctly modelled in path planning step or compensatory steps are taken during the build process, the geometrical accuracy of the final part will be compromised. Therefore, when the proposed cooling method is implemented in WAAM, it should also be considered in the path planning strategy to ensure the geometrical accuracy of the product. It should be noted that specimens S5 and S6 were produced at different deposition travel speeds, so the bead dimensions would be different to S1, even before the additional influence of active interpass cooling.

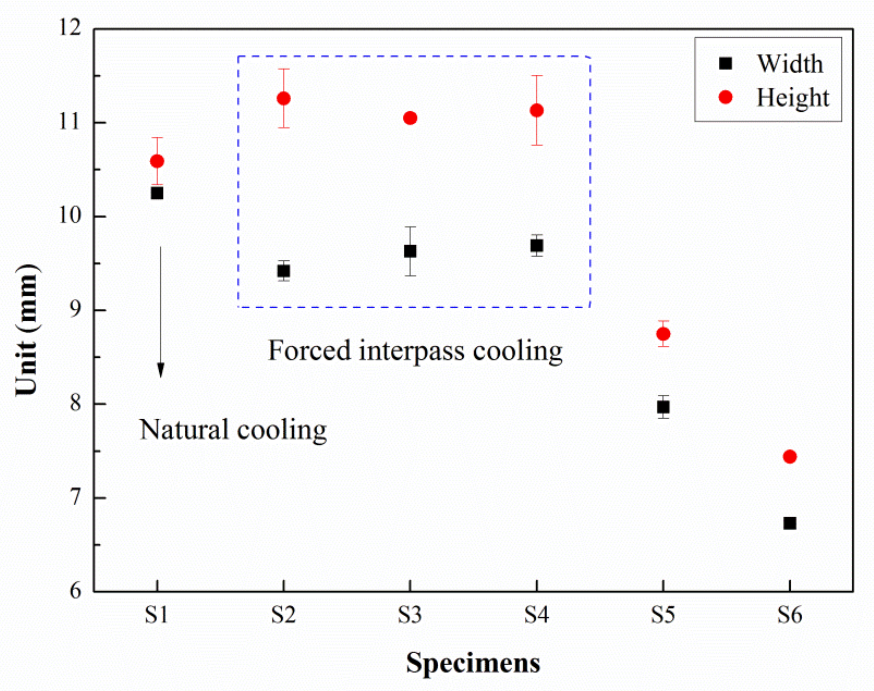

Fig.7 The wall dimensions of all fabricated specimens

\subsection{Thermal distortion}

Fig.8 shows the simulation results for the distortion of the additively manufactured specimens. Fig.9 further displays the distortion of the substrate, examined along the longitudinal direction (travel direction) and transverse direction (perpendicular to the travel direction). When adding sequential interpass cooling to the deposition process, the produced part sees an $81 \%$ and $69 \%$ in the maximum reduction of the longitudinal and transverse distortion, respectively. The simulation results are basically consistent with experimental observation, which indicates that 
active interpass cooling is able to significantly mitigate the distortion issues in WAAM parts.

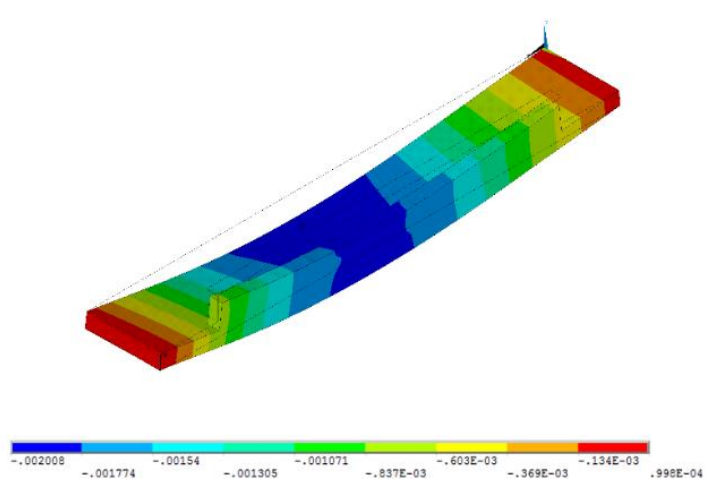

(a) S1

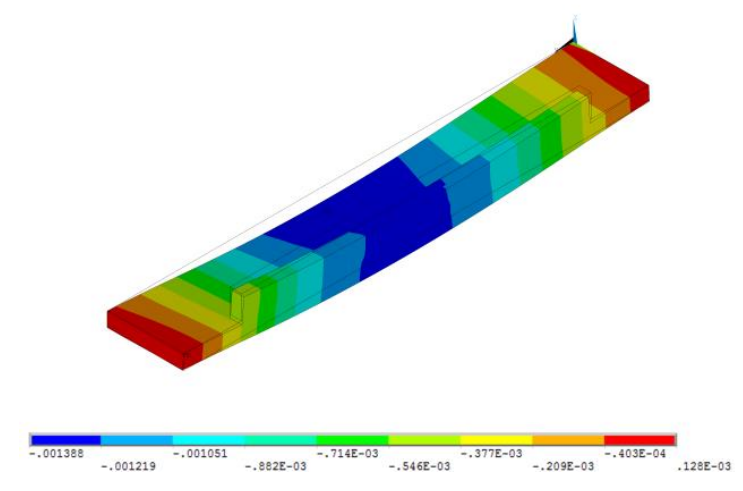

(c) S3

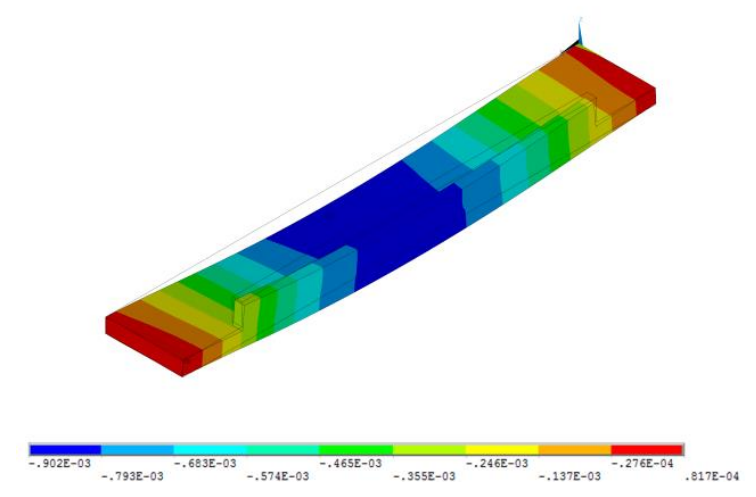

(e) S5
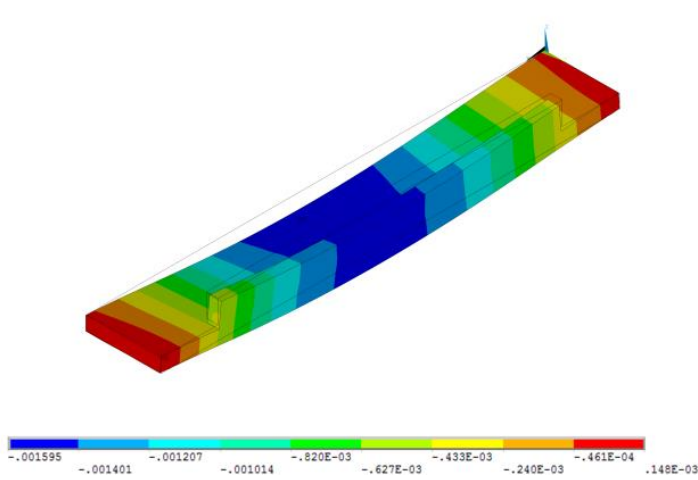

(b) S2

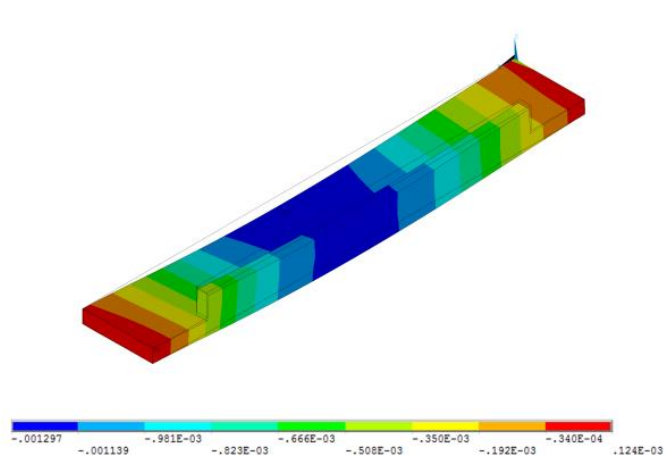

(d) S4

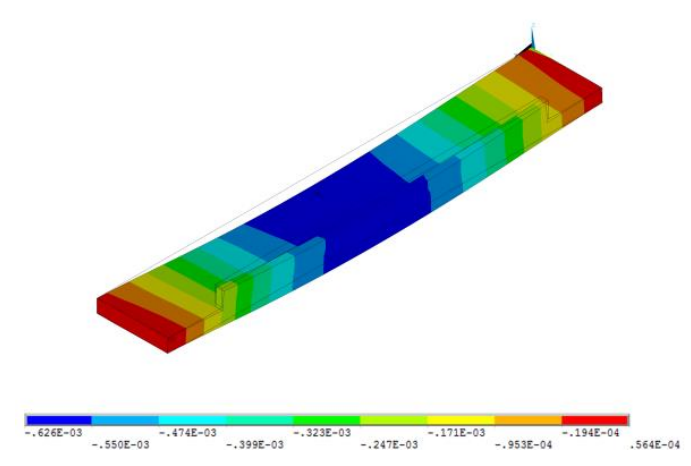

(f) S6

Fig.8 Simulation results for the distortion of produced samples: (a) S1; (b) S2; (c) S3; (d) S4; (e) S5; (f) S6. 

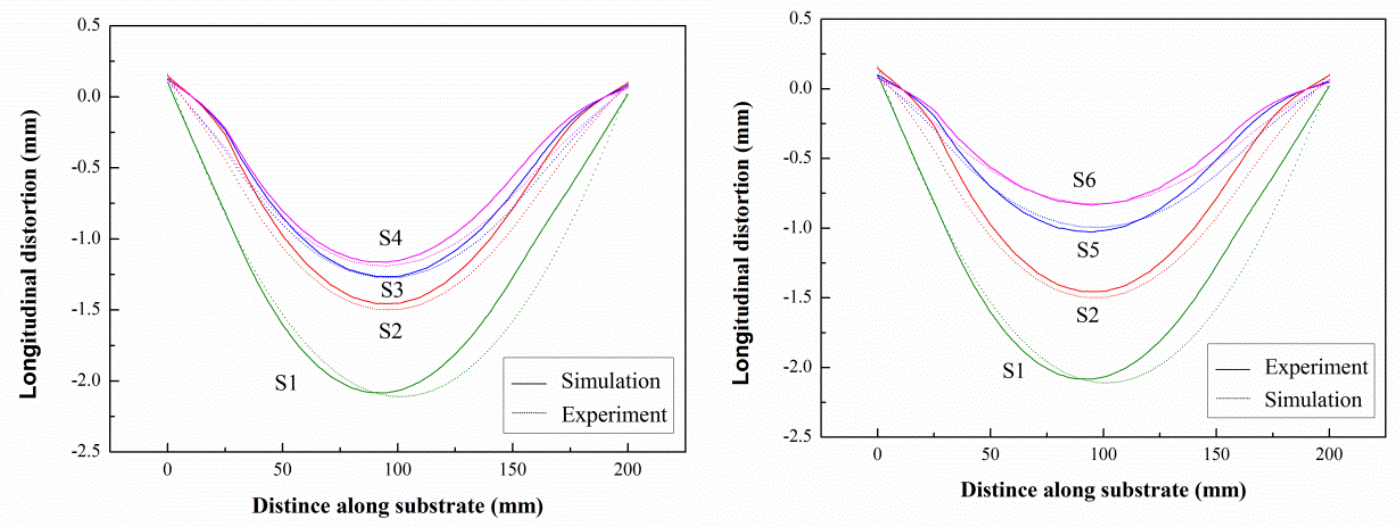

(a) Longitudinal distortion
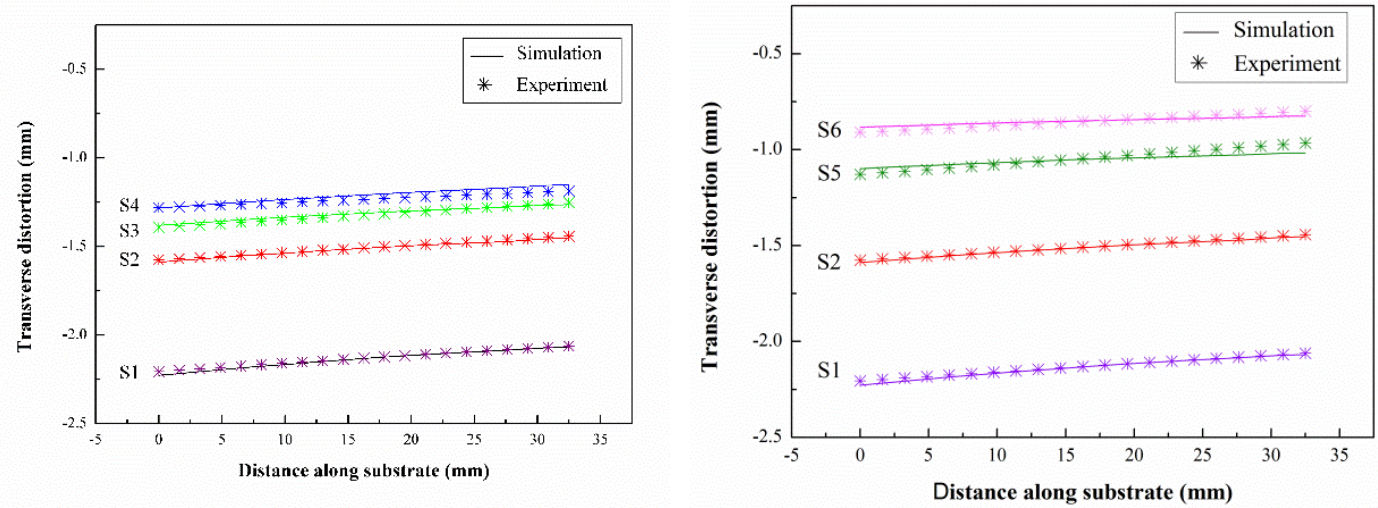

(b) Transverse distortion

Fig.9 The thermal distortion of as-deposited specimens: (a) longitudinal distortion and (b) transverse distortion of half of substrate.

Due to non-uniform thermal contraction in the melt area, shrinkage, which is inhibited by underlying materials, takes place. The generation and development of shrinkage induces a tensile stress in the newly added top layer and a compressive stress is generated in underlying layers, which leads to a localized distortion in the deposited areas. During deposition, theses localized distortions, particularly in the first few layers, accumulate along the build direction. These lead to distortion and dimensional variation in the final part, as shown in Fig.10(a). In extreme cases, complete loss of the planned bead deposit dimensional control may occur. Besides, 
the WAAM-produced component experiences non-uniform thermal expansion and contraction under alternate re-heating and re-cooling cycles during deposition. As the component geometry is built, there is a natural change in the mode of heat transfer; primary with conduction of heat through the base substrate for the surrounding atmosphere, followed by increasing amounts of radiation and convection as the geometry builds, as shown in Fig.10(b). This means an obvious heat accumulation generates, which significantly increase the thermal distortion of final produced part. It is worth noting that part distortion reached a steady-state condition after several layers of build, due to the thermal strain reaching a nearly constant value [7]. Obvious distortion is generated along the travel direction attributable to the large thermal strain.

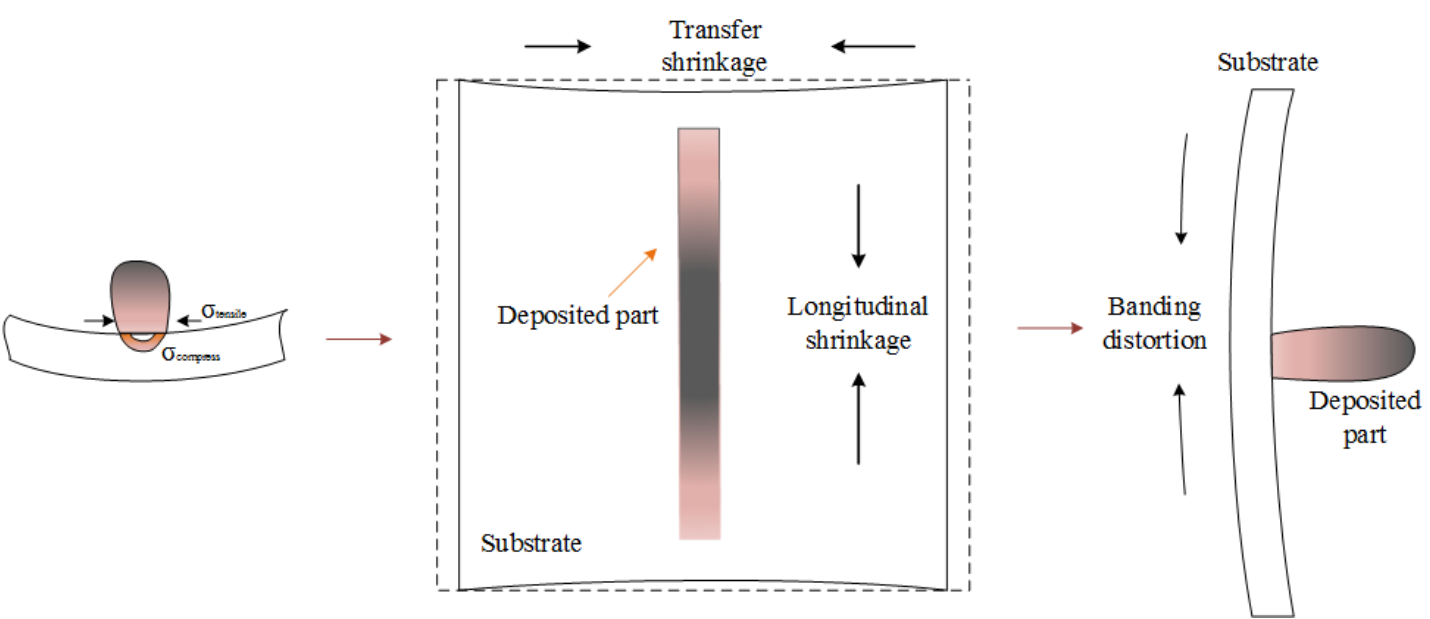

(a) 


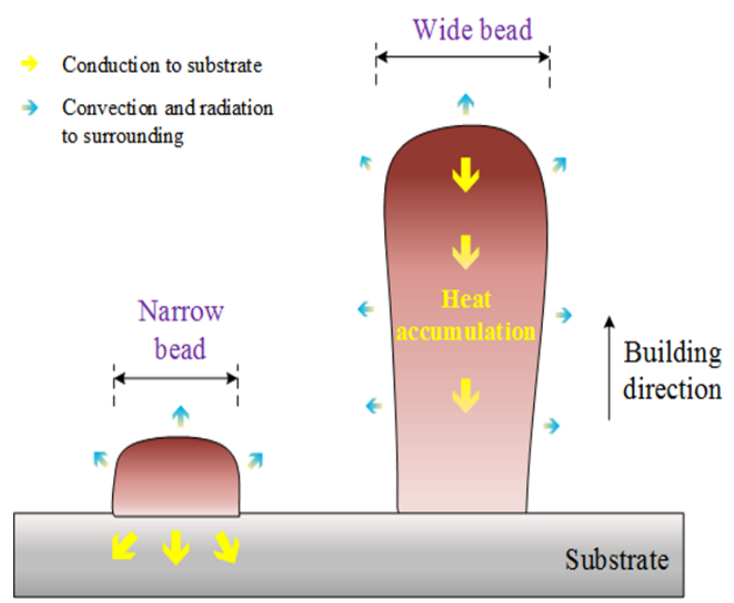

(b)

Fig.10 The distortion mechanism in WAAM-fabricated Ti6Al4V process: (a) The distortion generation and development; (b) The heat transfer mode along the build height

Two main parameters, cooling gas flow rates and cooling time, are primarily responsible for the change in distortion of parts produced using the WAAM process with active interpass cooling. Mukherjee et al. [19] reported that thermal distortion of an additively manufactured part is dependent on a strain parameter, $\varepsilon^{*}$ :

$$
\begin{gathered}
\varepsilon *=\frac{\beta \Delta T t H^{\frac{3}{2}}}{E I F \sqrt{\rho}} \\
F=\frac{\alpha \tau}{w^{2}}=\frac{\alpha}{V} L
\end{gathered}
$$

where $\beta$ is the volumetric coefficient of thermal expansion, $E$ is the elastic modulus, $\Delta T$ is the maximum rise in temperature, $I$ is the moment of inertia of the substrate, $t$ is the characteristic time, $H$ is the heat input per unit length, $F$ is the Fourier number which is the ratio of the heat dissipation rate to heat storage rate, $\rho$ is the density of the alloy wire, $\alpha$ refers to thermal diffusivity, $\tau$ is characteristic time scale, $w$ is deposition length, $V$ is the traveling speed, and $L$ is the length of molten pool. Eq (2) and (3) demonstrate that both reducing heat accumulation and improving heat dissipation in a deposited part can result in a high Fourier number and low peak 
temperature, leading to a low thermal strain and distortion for the additively manufactured part [7]. With the assistance of active interpass cooling, the heat stored in the deposit can be quickly dissipated, contributing to less heat accumulation and thus low thermal strain. This is useful for the reduction of distortions that are difficult to mitigate with mechanical methods. When active interpass cooling used, the inherently shortened dwell period also brings less distortion accumulation, contributing to the desired geometrical performance of the final produced part. Additionally, Ti6A14V is a two phase (alpha + beta) titanium alloy that undergoes an allotropic phase transformation. On the re-heating during short dwell time by active interpass cooling, the presence of these two phases across the solid-state stability range cannot easily introduce a number of different complexities, including a difference in the thermal expansion properties of the two phases which can create an annealing of the residual stress and distortion [20]. Hence, the interpass cooling to used material system provides resistance to distortion. The similar result can also be found in the laser additively manufactured Ti6Al4V part [21].

In comparison to the results produced by solely adjusting the cooling gas flow rate (Group II), the effect of adjusting both the deposition speed and the cooling time (Group III) provides improved mitigation of distortion, which may be attributed to the combined effects of reduced heat input at deposition and even further shortened dwell time between deposits, creating greater average heat dissipation per unit time. From this point of view, if active interpass cooling is used, distortion control is more effective through setting the cooling time rather than purely varying cooling gas flow 
rate. By this approach, both cooling efficiency improvement and cooling gas savings can be achieved. However, the shape of the deposited material is necessarily different, as shown in Fig.7, so the path planning algorithm must compensate for such changes.

Implementing an active interpass cooling using compressed $\mathrm{CO}_{2}$ process can restrict the possible distortion through cooling local to layer bead and then resultant decrease of heat accumulation which is a key factor in determining the distortion within build part. Therefore, whatever specimen size is to be captured, it assists WAAM to reduce total heat flux and impact of thermal cycling, as well as set new boundary conditions. This has been proven effective in distortion improvement for WAAM-produced component. Unfortunately, interpass cooling alone has not proved to be capable of eliminating distortion completely due to unrestrained shrinkage and deformation, and moreover, they require extra fixtures that might restrict the flexibility of changes in terms of the part geometry. In the future work, we will continue more work on the specific WAAM-fabricated part.

The primary focus of this paper has been to propose and evaluate an innovative method for low distortion WAAM fabrication of metal components, promoting high manufacturing efficiency. Active interpass cooling using compressed $\mathrm{CO}_{2}$ is effective in reducing distortion of WAAM components and improving dimensional accuracy. Future work will investigate the residual stress distribution in components which are produced by different cooling times and cooling gas flow rates during fabrication.

\section{Conclusion}

In this study, an innovative WAAM process with active interpass cooling using 
compressed $\mathrm{CO}_{2}$ was developed for fabricating Ti6Al4V wall structures. The thermal behavior, geometrical features, and distortion characteristics of as-fabricated specimens were investigated and discussed. The following conclusions could be drawn:

(1) By applying active interpass cooling between deposition of layers, the build times have been reduced by at least $80 \%$.

(2) By means of active interpass cooling, significant distortion reduction is possible in produced parts due to rapid heat removal and consequently decreased heat accumulation during deposition. It was observed that simultaneously altering deposition and cooling times has a greater mitigation effect on thermal distortion mitigation than only adjusting the cooling gas flow rate, which is possibly related to the difference in the overall heat dissipation per unit time.

(3) Since active interpass cooling affects deposition process, the path planning strategy should take this into consideration if it is carried out, and more optimized strategies for distortion control should be considered from the cooling time point of view.

\section{Acknowledgements}

The authors gratefully acknowledge the China Scholarship Council for financial support (NO. 201506680056) the UOW Welding and Industrial Automation Research Centre for the use of their facilities.

\section{References}


[1] Williams SW, Martina F, Addison AC, et al. Wire + Arc Additive Manufacturing. Mater Sci Technol. 2016;32:641-647.

[2] Ding D, Pan Z, Cuiuri D, et al. Wire-feed additive manufacturing of metal components: technologies, developments and future interests. Int J Adv Manuf Technol. 2015;81:465-481.

[3] Wu B, Pan Z, Ding D, et al. A review of the wire arc additive manufacturing of metals: properties, defects and quality improvement. J Manuf Process. 2018;35:127-139.

[4] Brandl E, Baufeld B, Leyens C, et al. Additive manufactured Ti-6Al-4V using welding wire: comparison of laser and arc beam deposition and evaluation with respect to aerospace material specifications. Phys Procedia. 2010;5:595-606.

[5] Collins PC, Brice DA, Samimi P, et al. Microstructural Control of Additively Manufactured Metallic Materials. Annu Rev Mater Res. 2016;46:63-91.

[6] Wu B, Ding D, Pan Z, et al. Effects of heat accumulation on the arc characteristics and metal transfer behavior in Wire Arc Additive Manufacturing of Ti6Al4V, J Mater Process Technol. 2017;50:304-312.

[7] Mukherjee T, Manvatkar V, De A, et al. Mitigation of thermal distortion during additive manufacturing. Scripta Mater. 2017;127:79-83.

[8] Denlinger ER, Chapter 11 - Mitigation of Distortion in Large Additive Manufacturing Parts*, Thermo-Mechanical Modeling of Additive Manufacturing, Butterworth-Heinemann2018, pp. 183-195.

[9] Michaleris P. Minimization of welding distortion and buckling: modelling and implementation, Elsevier. 2011;p.274.

[10] Masubuchi K. Analysis of welded structures: Residual stresses, distortion, and their consequences, Elsevier. 2013;33:372.

[11] Cao J, Gharghouri MA, Nash P. Finite-element analysis and experimental validation of thermal residual stress and distortion in electron beam additive manufactured Ti-6Al-4V build plates. J Mater Process Technol. 2016;237:409-419. [12] Montevecchi F, Venturini G, Grossi N, et al. Finite Element mesh coarsening for 
effective distortion prediction in Wire Arc Additive Manufacturing. Addit Manuf. 2017;18:145-155.

[13] Ding J, Colegrove P, Mehnen J, et al. Thermo-mechanical analysis of Wire and Arc Additive Layer Manufacturing process on large multi-layer parts. Comput Mater Sci. 2011;50:3315-3322.

[14] Zhang Y, Ying Y, Liu X, et al. Deformation control during the laser welding of a Ti6A14V thin plate using a synchronous gas cooling method. Mater Des. 2016;90:931-941.

[15] Colegrove PA, Donoghue J, Martina F, et al. Application of bulk deformation methods for microstructural and material property improvement and residual stress and distortion control in additively manufactured components. Scripta Mater. 2017;135:111-118.

[16] Schenk T, Richardson IM, Kraska M, et al. A study on the influence of clamping on welding distortion. Comput Mater Sci. 2009;45:999-1005.

[17] Guan, Q, Zhang C, Guo D. Dynamically controlled low stress no distortion welding method and its facility, Chinese patent. No. 93101690.8. 1993.

[18] Wu B, Pan Z, Ding D, D. et al. The effects of forced interpass cooling on the material properties of wire arc additively manufactured Ti6Al4V alloy. J Mater Process Technol. 2018;258:97-105.

[19] Mukherjee T, Zuback J, De A, et al. Printability of alloys for additive manufacturing. Sci Rep. 2016;6:19717.

[20] Elmer J, Palmer T, Babu S, et al. In situ observations of lattice expansion and transformation rates of $\alpha$ and $\beta$ phases in Ti-6Al-4V, Mater Sci Eng A 2005;391:104-113.

[21] Denlinger ER, Heigel JC, Michaleris P, et al. Effect of inter-layer dwell time on distortion and residual stress in additive manufacturing of titanium and nickel alloys. $\mathrm{J}$ Mater Process Technol. 2015;215:123-131. 
2019-02-26

\section{Mitigation of thermal distortion in wire arc additively manufactured Ti6Al4V part using active interpass cooling}

Wu, Bintao

Maney Publishing

Wu B, Pan Z, Chen G, et al., (2019) Mitigation of thermal distortion in wire arc additively manufactured Ti6AI4V part using active interpass cooling. Science and Technology of Welding and Joining, Volume 24, Issue 5, 2019, pp. 484-494

https://doi.org/10.1080/13621718.2019.1580439

Downloaded from Cranfield Library Services E-Repository 